\title{
Organism Strain
}

National Cancer Institute

\section{Source}

National Cancer Institute. Organism Strain. NCI Thesaurus. Code C14419.

A population or type of organisms that is genetically different from others of the same species and possessing a set of defined characteristics. 